\title{
The Design of Smart Education Environment and Its Implementation
}

\author{
Hongkai Lin \\ Wuhan Business University, Wuhan, Hubei, 430056 \\ linhk@wbu.edu.cn
}

\begin{abstract}
Keywords: Smart Education Environment. Implementation. Design.
Abstract. We generally try to understand the concept of smart education from the perspective of ecology. The so-called smart education is a sort of education information ecology, whose operation should be backed up by modern information technology, including the Internet of Things and cloud computing etc., and characterized by intellectualization and information perceptualization. This article summarizes the relevant concept and typical features of smart education and proposes a design of smart education environment and its implementation.
\end{abstract}

\section{Introduction}

In the $21^{\text {st }}$ century, the mankind has ushered into the information age. With the support of information technology, the material world has started to become humanized in that communication is not limited among human beings but extended to between humans and things. Therefore, the information world is also called the "smart world". The concept of smart education has been produced against this background. As education is the foundation for the prosperity and development of a nation, many nations have started to study how to construct an environment of smart education.

\section{Summary of Smart Education.}

Relevant Concepts of Smart Education. There are many concepts related to smart education, mainly including the following: the first is digital education, which is a modernized form of education based on digital technology. In fact, smart education is developed from the basis of digital education, and may be understood as the extension of digital education. In terms of developmental objective, digital education aims at improving teaching efficiency, while smart education targets at training smart talents; in terms of core technology, digital education relies on multi-media and the Internet, etc., while smart education relies on big data and cloud computing, etc.; in terms of teaching methods, digital education centers on teachers and is supported by other methods, while smart education focuses on learners, and is conducted mainly through open and interactive teaching[1].

The second is IT application in education, which is using information technology to accelerate education applying IT, while smart education is the extension and development of IT application in education and a new approach for realizing the objective of quality-oriented education. The current society has enters into an age that respects knowledge. [2] All countries attach unprecedented importance to education, and the education department has taken smart education as an important strategy when pushing forward the IT application in education; various policies of IT application in education, in turn, have also created external conditions for the development of smart education.

The last is educational modernization, which is in fact a very broad concept. In terms of teaching concept, it is more innovative than before; in terms of technology, it is more reliant on the Internet of Things and the cloud computing, etc.; in terms of teaching methods, it has richer and opener methods; in terms of hardware conditions, school buildings and teaching equipment are more advanced, laying a foundation for realizing lifelong, diversified and individualized education. Smart education is an important goal of modernized education, which is to train more smart talents with distinct individuality and creativity.

Typical Features of Smart Education. Compared with traditional education, smart education takes on educational and technological characteristics different from before. In terms of educational characteristics, smart education effectively integrates various disciplines with information technology, which is not a kind of integration in the normal sense, but one of great depth requiring 
that teachers and students can solve practical educational problems by flexibly using information technology. It does not focus on information technology itself, but produces a result that the sum is greater than the parts by using the integration of technology and discipline in the whole teaching activity[3]. Besides, smart education re-defines the education environment in that the whole educational space is not separated, but all educational sites are connected by the network system, including schools, libraries and families. In this way, learning is free from the constraints set by time and place, and learners can study anytime and anywhere depending on their own needs.

In terms of technological characteristics, smart education integrates all relevant technologies to realize comprehensive utilization[4]. One technological characteristic is situational perception, which covers not only the perception of external learning environment such as the physical location and time of learning, but also the perception of internal learning state such as learning state and cognitive habits; another technological characteristic is seamless connection in that smart education realizes the seamless integration of the real world and the virtual world on one hand and supports multi-terminal access on the other hand (that is, learners can use a terminal device to acquire any learning resource in a system, while seamless switch can be realized between all terminals so as to realize data synchronization, and educators can establish learning communities according to actual needs to create relevant learning situation for learners and facilitate the communication among learners.)

\section{The Construction of the Smart Education Environment.}

The Construction of Smart Education Environment.Constructing the smart education environment is mainly to build two spaces: one is the learning space, where learners can conduct learning activities, and the other is the education space, which is mainly for providing teachers with supplementary teaching means and methods. The two spaces interact with each other for the purpose of realizing the objective of smart education.

The Construction of the Learning Space. The learning space has the following four modules: the first module is to manage information, which is mainly responsible for recording and protecting learners' basic information. Learners can set permissions for access to the learning contents they have generated so as to realize communication while ensuring information security. Besides personal information, the information managed by the system also includes information about learning activities, which is recording the data of each learning process to provide a basis for the evaluation of education results. Second, learning contents can be generated. The learning space includes various supporting functions, and learners, after becoming familiar with these functions, can create their unique learning activities and thus generate learning contents. On one hand, teachers can evaluate learners' direction, methods and achievement based on the learning contents; on the other hand, learners can realize communication based on these contents. The third module is to connect with other people. This module is mainly serving for collaborative learning. Learners can hold dialogues with their partners through the system so as to get inspired and create new knowledge. Fourth, learners can share learning results. E-learning portfolio is the main tool for the operation of this module, which can be used to create electronic portfolios, arrange and demonstrate their achievements. E-learning portfolios include learners' complete information, including learning contents and conversation contents[5].

The Construction of the Teaching Space. Similar to the learning space, the construction of the teaching space also consists of four modules: The first one is still information management, which includes, besides teachers' basic information, teachers' process of lesson preparation, the material utilization and students' comments. The second module is to generate teaching contents. Teachers can design teaching contents within the teaching space and effectively utilize its teaching resources; the teaching contents generated can be shared in the space, and other teachers may raise relevant comments for revision. The third module is still to connect with other people. Different from the learning space, the connection here mainly includes two parts: the first part is to dialogue with students, from which teachers can acquire students' real thoughts, learn their actual needs; students can bring forward opinions to teachers anonymously, based on which teachers can reasonably adjust their teaching contents and methods. The fourth module is to share teaching achievements; similar to 
the sharing of learning achievements, this process mainly uses E-teaching portfolios, including teaching resources and accomplishments as well as students' learning process, based on which teachers can give personalized guidance[6].

The Implementation of the Smart Education Environment. The implementation of the smart education environment is related to the specific education environment and technological level. Factors such as situational perception, teaching cell and learning cell should be taken into comprehensive consideration. The specific implementation process can be divided into the following steps:

Establishing an Underlying Database. The underlying database consists of two parts: the first part is the raw data base including unprocessed raw data, with E-learning portfolios and teaching portfolios as its main sources; the other part is the aggregated database, of which the data comes from the raw database, and should be analyzed and aggregated to extract data of higher use ratio and "pack" them to form "data packets". Teachers and students can directly use these data packets, as these resources are complete instead of some scattered data. The aggregated information database has the function of self-adaptation algorithm, and is therefore dynamic, able to realize automatic updating. This kind of automatically updated underlying database gives great vitality to the smart education environment, as the real-time updating of the underlying database can guarantee that the data retrieved and used by the whole system are changing in real time, and the data information truly provided to teaching practices and activities can timely reflect the changes in relevant disciplines, which guarantees that teaching activities are highly adapted to the latest industry research and teaching theory field. We can say that the design of the dynamic underlying database is another reflection of the smart education environment. The distance between the society and classroom is truly narrowed and the smart education environment is realized[7].

Cloud Analysis Process. This step is mainly to further process the information transmitted from the database, and the information after being processed should be individualized and labeled as for share before being packed to form learning cells and teaching cells with more concrete and pertinent contents. This step mainly consists of two parts. The first part is expectation analysis which includes three sections: the first section is social expectation, which is what requirements the society has for talents and what knowledge and skills they should have; the second section is teachers' expectation, which may be understood as teaching objectives and what knowledge students are expected to master; the third section is students' expectation, which mainly refers to students' learning interest, and the information about such expectation may be acquired through investigation and survey. The second part is smart content analysis. First, it should be able to adapt to the changes of utilization devices and can memorize utilization contents and progress[8]. Second, this step should have RSS (Really Simple Syndication) self-adaptive function and the information should be individualized. For example, this step should be able to work out what resources are most widely applied in which disciplines and what the main forms of use are. Such information may be acquired through two approaches, namely, being filled out by users and through big data analysis.

The Use of Terminal Users. The main value for the construction of the modern smart education environment may lie in the use of terminal users, as the design of all smart systems and the construction of smart environment are for serving the use of users. Therefore, in the course of terminal users' use, we should attach great importance to customer experience. The course of collecting and processing data is all for serving the use of terminal users. We should conduct simulation analysis of processed data and realize smart push of resources so that users can acquire the information they need. After being transmitted to electronic teaching portfolios and learning portfolios, resources will be automatically displayed on terminal devices for users to use, including a course of situational perception for the purpose of displaying resources in a more reasonable way. For example, if it is perceived that the Internet speed is slow and videos are included in the resources, other contents may be displayed first, while videos are being back buffered[9]. 


\section{Conclusions}

Smart education is to provide students and teachers with a more convenient and smarter learning environment. In the learning space, learners may participate in individualized learning activities according to their own likes and demands; in the teaching space, teachers may use rich resources to design more reasonable teaching contents, while providing personalized guidance for students to realize their teaching objectives. The whole course should be implemented by establishing an underlying database, cloud analysis and use of terminal users.

\section{Acknowledgements}

This work was financially supported by Education and Teaching Reform Research Project of Wuhan Business University :Smart Cloud Classroom Building Research of Wuhan Business University ( 2016N002 )

\section{References}

[1] Huiping Cui. Modern Distance Education. No S6(2014),p.108-110. (In Chinese)

[2] Xianmin Yang.et al, China Educational Technology. No S1(2015),p.85-90. (In Chinese)

[3] Bakia, M. , Murphy, R. , Anderson, K. , \& Estrella-Trinidad, G. International experiences with technology in education: Final report[R]. U. S. Department of Education, Office of Educational Technology.(2011), 12(5), p11-25.

[4] Surong Jiang.et al, Computer Science.No S1(2014),p409-413. (In Chinese)

[5] Lin Chen.e-Education Research No 3(2015),p.119-125. (In Chinese)

[6] Chang, T. W. , Hsu, J. M. , \&Yu, P. T. (2011). A comparison of single-and environment in programming language ; Cognitive loads and learning effects[J]. Educational Technology \& Society . No S2(2011), p188-200.

[7] Hequn Wang.China Mediatech. Vol.25 (2008),p60-64.(In Chinese)

[8] Razak, S. F. A. Cloud computing in Malaysia universities[C]. Innovative Technologies in Intelligent Systems and Industrial Applications (CITISIA 2009) (2009) ,p101-106.

[9] Xue Han. Electronic Design Engineering.No 24(2011),p41-43.(In Chinese) 